Linköping Studies in Science and Technology

Thesis No. 1737

\title{
Silicon Oxynitride Thin Films Grown by Reactive HiPIMS
}

Tuomas Hänninen

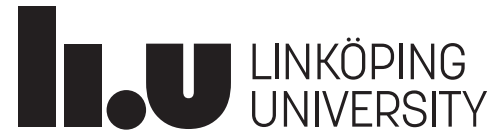

Thin Film Physics Division Department of Physics, Chemistry, and Biology (IFM)

Linköping University, SE-581 83 Linköping, Sweden

Linköping 2016 

Linköping Studies in Science and Technology

Thesis No. 1737

\section{Silicon Oxynitride Thin Films Grown by Reactive HiPIMS}

Tuomas Hänninen

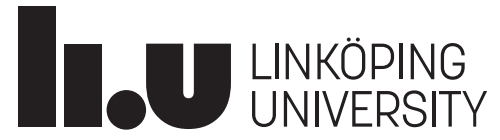

Thin Film Physics Division Department of Physics, Chemistry, and Biology (IFM)

Linköping University, SE-581 83 Linköping, Sweden

Linköping 2016 
(C) Tuomas Hänninen ISBN 978-91-7685-879-0

ISSN 0280-7971

Printed by LiU-Tryck 2015 
Amorphous silicon oxynitride $\left(\mathrm{SiO}_{\mathrm{x}} \mathrm{N}_{\mathrm{y}}\right)$ thin films were grown by reactive high power impulse magnetron sputtering from a pure silicon target in $\mathrm{Ar} / \mathrm{N}_{2} \mathrm{O}$ plasmas. The elemental composition of the films was shown to depend on the target surface conditions during the film deposition, as well as on the reactive gas flow rate. When the target was sputtered under poisoned surface conditions, the film composition was predominantly silicon oxide, whereas films deposited in the transition regime between poisoned and metallic target surface conditions showed higher nitrogen concentrations, as measured by X-ray photoelectron spectroscopy (XPS) and elastic recoil detection analysis (ERDA). The different target surface conditions were identified based on the evolution of the target current waveforms upon variation of the deposition parameters. The average electron temperatures during the peak target current were determined by Langmuir probe measurements, to assist with the explanation of the observed target current behavior and target poisoning characteristics.

The chemical composition of the films was shown to range from silicon-rich to effectively stoichiometric silicon oxynitrides, where no $\mathrm{Si}-\mathrm{Si}$ contributions were found in the XPS Si 2 p core level spectra. The film optical properties, the refractive index $n$ and the extinction coefficient $k$, were shown to depend on the film chemical bonding, with the effectively stoichiometric films displaying optical properties falling between those of $\mathrm{SiO}_{2}$ and $\mathrm{Si}_{3} \mathrm{~N}_{4}$. 


\section{Acknowledgments}

I gratefully acknowledge the financial support by European Union's Seventh Framework Program (FP7/2007-2013) under the LifeLongJoints Project, Grant Agreement No. GA-310477, and by the Swedish Government Strategic Research Area in Materials Science on Functional Materials at Linköping University (Faculty Grant SFO-Mat-LiU No. 2009-00971).

I want to thank my supervisor Hans Högberg for his guidance. I also express my gratitude to my co-supervisors; to Susann Schmidt for her tireless effort to push the project forward, and to Lars Hultman for his insights regarding the written work. In addition, my gratitude goes to my co-authors and to all those who have assisted me at any point along the way. 

1 Introduction 1

1.1 Material properties of silicon oxynitride . . . . . . . . 2

2 Thin film deposition and process characterization 5

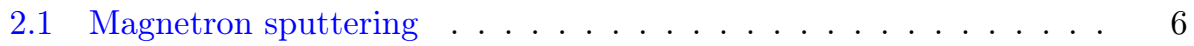

2.1.1 High power impulse magnetron sputtering . . . . . . . . 8

2.1 .2 Reactive HiPIMS . . . . . . . . . . . . . . . . . 9

2.1.3 HiPIMS in oxygen-containing atmospheres . . . . . . . . 9

2.2 Langmuir probe. . . . . . . . . . . . . . . . . . 10

2.3 The effect of HiPIMS parameters on $\mathrm{SiO}_{\mathrm{x}} \mathrm{N}_{\mathrm{y}}$ material properties . 11

3 Thin film characterization $\quad 13$

3.1 X-ray photoelectron spectroscopy . . . . . . . . . . . . 13

3.2 Elastic recoil detection analysis $\ldots \ldots \ldots \ldots \ldots \ldots$

3.3 X-ray reflectivity . . . . . . . . . . . . . . . . . 15

3.4 Residual stress measurement . . . . . . . . . . . . . . . . . . 16

3.5 Spectroscopic ellipsometry . . . . . . . . . . . . . . . . 17

4 Results and included papers $\quad 21$

4.1 List of publications . . . . . . . . . . . . . . . . . 21

4.2 Summary of included papers _. . . . . . . . . . . 22

Bibliography 23

$\begin{array}{ll}\text { Paper I } & 31\end{array}$

$\begin{array}{ll}\text { Paper II } & 41\end{array}$ 


\section{CHAPTER 1}

\section{Introduction}

Amorphous thin films have applications ranging from antireflective coatings used on solar cells to biocompatible wear resistant coatings on medical implants. One commonly used ceramic amorphous thin film material is silicon oxynitride $\left(\mathrm{SiO}_{\mathrm{x}} \mathrm{N}_{\mathrm{y}}\right)$. Silicon oxynitride is widely used in optoelectronics as graded-index layers [1, 2], waveguides [3, 4], and surface passivation layers [5, 6], due to its favorable optical and electrical properties. Especially the tunable refractive index makes $\mathrm{SiO}_{\mathrm{x}} \mathrm{N}_{\mathrm{y}}$ well-suited for optical applications. [7] Furthermore, also the mechanical properties, such as residual stress and hardness can be controlled through the elemental composition. [8-10] Lately, there has been a growing interest for the use of $\mathrm{SiO}_{\mathrm{x}} \mathrm{N}_{\mathrm{y}}$ coatings in medical implants due to the good hemocompatibility of the material along with the suitable mechanical properties. [11, 12] The reason for such a wide range of applications for $\mathrm{SiO}_{\mathrm{x}} \mathrm{N}_{\mathrm{y}}$ is the possibility to control its material properties by adjusting the amount and ratio of oxygen and nitrogen in the material. This yields properties ranging from those of amorphous silicon to amorphous silicon oxide and nitride, or such shown by mixed compositions between the three. $[13,14]$

Commonly $\mathrm{SiO}_{\mathrm{x}} \mathrm{N}_{\mathrm{y}}$ thin films have been prepared by either chemical vapor deposition (CVD) or by magnetron sputtering. The CVD methods are limited by hydrogen-containing precursor gases, resulting in $\mathrm{Si}-\mathrm{H}$ and $\mathrm{N}-\mathrm{H}$ chemical bonding in the films, which causes absorption losses in the near-infrared wavelength range. $[3,13,15]$ Two reactive gases, $\mathrm{O}_{2}$ and $\mathrm{N}_{2}$, are usually employed when $\mathrm{SiO}_{\mathrm{x}} \mathrm{N}_{\mathrm{y}}$ is synthesized by magnetron sputtering. [16-18] The two-gas approach results in nonlinear target effects due to the inherently different reactivities of oxygen and nitrogen, since oxygen as the more reactive element is more likely to form a compound on the Si-target. [19] Additional equipment, such as a reactive gas pulsing process or a feedback loop based on monitoring the discharge current or voltage, can be employed to limit the $\mathrm{O}_{2}$ flow during the process, and to reduce the nonlinear target effects caused by the different reactivities of oxygen and nitrogen. 


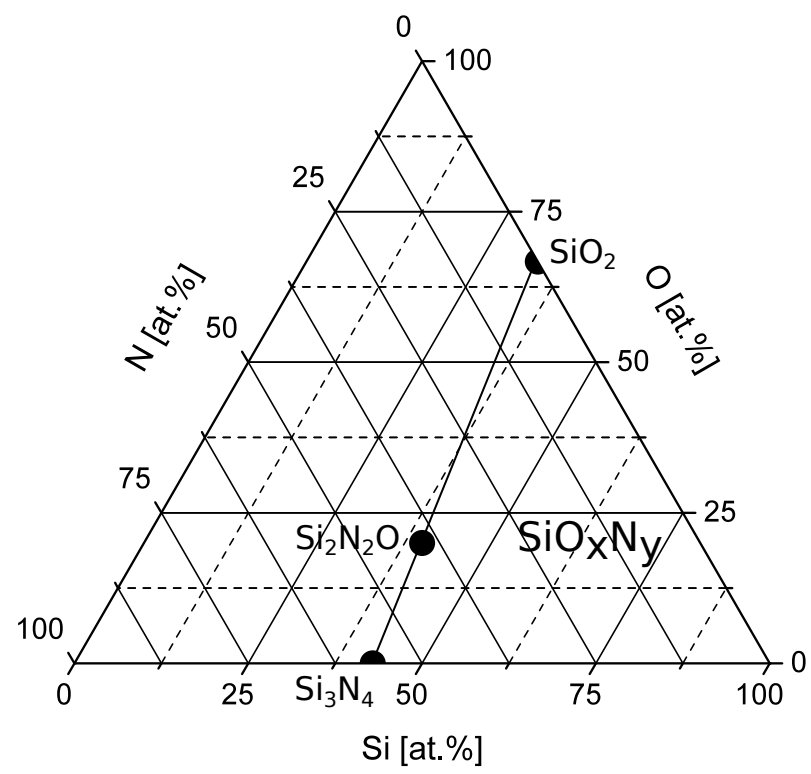

Figure 1.1. A ternary plot of the $\mathrm{Si}-\mathrm{O}-\mathrm{N}$ system.

$[16,17,20]$

A new synthesis route for amorphous $\mathrm{SiO}_{x} \mathrm{~N}_{y}$ thin films by reactive high power impulse magnetron sputtering (rHiPIMS), using nitrous oxide $\left(\mathrm{N}_{2} \mathrm{O}\right)$ as a singlesource precursor gas, is presented in Papers I \& II. General aspects about thin film deposition by HiPIMS, details about rHiPIMS with oxygen-containing precursors, as well as the main thin film characterization methods used in the papers, are summarized in this thesis.

\subsection{Material properties of silicon oxynitride}

The $\mathrm{Si}-\mathrm{O}-\mathrm{N}$ system shows only one thermodynamically stable ternary compound with the composition $\mathrm{Si}_{2} \mathrm{~N}_{2}$ O. [21, 22] A ternary plot of the $\mathrm{Si}-\mathrm{O}-\mathrm{N}$ system is shown in Fig. 1.1. The chemical bonding in amorphous non-stoichiometric $\mathrm{SiO}_{\mathrm{x}} \mathrm{N}_{\mathrm{y}}$ can be described by two bonding models, the random mixture model (RMM) and the random bonding model (RBM). [23, 24] In RMM, separate phases of $\mathrm{SiO}_{2}$ and $\mathrm{Si}_{3} \mathrm{~N}_{4}$ are randomly distributed in the material, whereas in $\mathrm{RBM}$ the central $\mathrm{Si}$ atom is randomly bond to four $\mathrm{Si}, \mathrm{O}$, and/or $\mathrm{N}$ atoms. [23, 24] Commonly, the growth of $\mathrm{SiO}_{\mathrm{x}} \mathrm{N}_{\mathrm{y}}$ is more closely governed by RBM than by RMM, especially for sputter-deposited films, as the growth conditions are usually thermodynamically far from those required for the growth of separate $\mathrm{SiO}_{2}$ and $\mathrm{Si}_{3} \mathrm{~N}_{4}$ phases. [9, 25]

The material properties in the randomly bond $\mathrm{SiO}_{\mathrm{x}} \mathrm{N}_{\mathrm{y}}$ mostly depend on the ratio of $\mathrm{O}$ and $\mathrm{N}$ in the Si-matrix. This can be achieved by changing the reactive gas flow ratios in reactive sputtering, for example. [26] The relative permittivity of 
stoichiometric $\mathrm{SiO}_{\mathrm{x}} \mathrm{N}_{\mathrm{y}}$ can vary from $3.9\left(\mathrm{SiO}_{2}\right)$ to $7.4\left(\mathrm{Si}_{3} \mathrm{~N}_{4}\right)$. [27] The refractive index of $\mathrm{SiO}_{\mathrm{x}} \mathrm{N}_{\mathrm{y}}$ can be tailored from that of $\mathrm{SiO}_{2}(n \sim 1.5)$ to that of $\mathrm{Si}_{3} \mathrm{~N}_{4}$ $(n \sim 2.0)$ by adjusting the $\mathrm{O} / \mathrm{N}$ ratio in the material. $[1,2]$ Furthermore, the refractive index for understoichiometric $\mathrm{SiO}_{\mathrm{x}} \mathrm{N}_{\mathrm{y}}$ are found to range from $\mathrm{Si}_{3} \mathrm{~N}_{4}$ values to those recorded for amorphous $\mathrm{Si}(n \sim 4)$, depending on how much $\mathrm{O}$ and $\mathrm{N}$ is incorporated into the Si-matrix. [28-30] The total amount of $\mathrm{O}$ and $\mathrm{N}$ in $\mathrm{SiO}_{\mathrm{x}} \mathrm{N}_{\mathrm{y}}$ also affects the extinction coefficient $(k)$ values, the stoichiometric compound is found to be transparent $(k \sim 0)$ in the visible wavelength range, whereas for the understoichiometric compound the $k$ values increase as the amount of $\mathrm{Si}$ in the compound increases, finally reaching values recorded for amorphous $\mathrm{Si}$ $(k \sim 0.2) .[29,30]$

Mechanical properties, such as density, residual stress, and hardness, also depend on the the $\mathrm{O} / \mathrm{N}$ ratio of $\mathrm{SiO}_{\mathrm{x}} \mathrm{N}_{\mathrm{y}}$. The $\mathrm{SiO}_{\mathrm{x}} \mathrm{N}_{\mathrm{y}}$ density can vary from that of $\mathrm{SiO}_{2}\left(\sim 2.1 \mathrm{~g} / \mathrm{cm}^{3}\right)$ to that of $\mathrm{Si}_{3} \mathrm{~N}_{4}\left(\sim 3.0 \mathrm{~g} / \mathrm{cm}^{3}\right)$. [31, 32] The residual stress in CVD-grown films can change from compressive to tensile, depending on if the material is oxide-like or nitride-like, respectively. [8] Moreover, both the hardness $(H)$ and Young's modulus $(E)$ of stoichiometric randomly bond $\mathrm{SiO}_{\mathrm{x}} \mathrm{N}_{\mathrm{y}}$ films is found to increase as the film composition shifts from $\mathrm{SiO}_{2}$ to $\mathrm{Si}_{3} \mathrm{~N}_{4}, H$ from $\sim 10 \mathrm{GPa}$ to $\sim 20 \mathrm{GPa}$ and $E$ from $\sim 100 \mathrm{GPa}$ to $\sim 200 \mathrm{GPa}$. [9, 33] 
CHAPTER 2

Thin film deposition and process characterization

Physical vapor deposition (PVD) methods, such as magnetron sputtering, are widely used both in research and in industry to grow a wide range of thin films for various applications. In PVD, the film material is ejected from a solid or liquid target and is transported to the substrate as a vapor. Usually PVD methods have a line-of-sight substrate coverage, unlike chemical vapor deposition (CVD) and atomic layer deposition (ALD) methods. The line-of-sight coverage limits the use of complex-shaped substrates in PVD deposition. Some advantages of PVD over CVD and ALD methods are, for example, off-thermal equilibrium film growth, allowing the use of heat-sensitive substrate materials, and higher deposition rates, respectively. Ionized PVD (IPVD) methods, such as high power impulse magnetron sputtering (HiPIMS), can be used to overcome shortages associated with common PVD methods, and open up possibilities to further tailor the film properties while still maintaining the favorable aspects of PVD. [34, 35] 


\section{$2.1 \quad$ Magnetron sputtering}

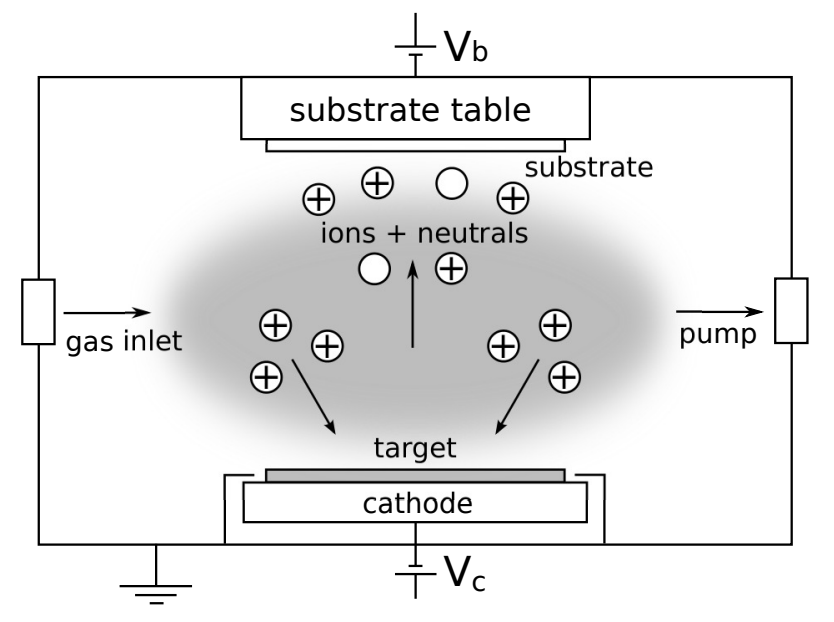

Figure 2.1. A schematic drawing of a magnetron sputtering setup.

Sputter deposition is a plasma-based PVD technique commonly employed in thin film growth. A potential difference applied between the negative cathode and a grounded anode causes ionization of the process gas, most commonly Ar, yielding a glow discharge. The ignition of the plasma is possible due to the ions and free electrons naturally present in the gas. More ions are created through collisions of the gas atoms with the free electrons, i.e., by electron impact ionization. Positive ionized gas atoms or molecules are accelerated towards the negatively biased cathode, where they sputter away material from the target. The ejected material travels to the substrate in the gas phase and condenses into a film. The grounded chamber walls and the substrate table can act as an anode, though usually a negative bias voltage is applied to the substrate table to exceed the floating potential and to achieve reproducible deposition conditions. [36, 37]

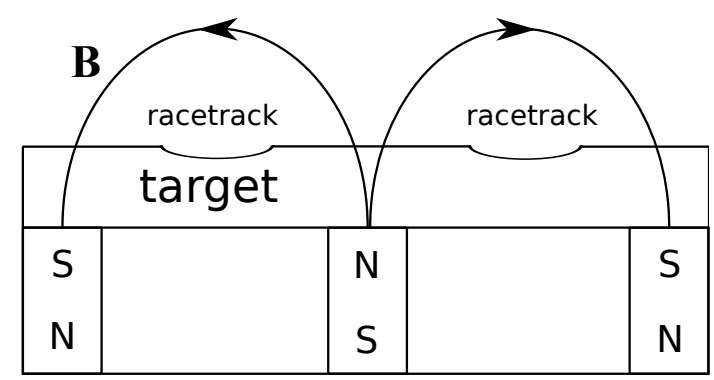

Figure 2.2. A drawing depicting the orientation of magnetic field lines in a simple balanced magnetron sputtering setup. 
In a magnetron sputtering setup electrons are confined into a magnetic field near the target surface. Increased amount of electrons near the target surface enhances the level of ionization of the working gas and results in greater plasma density in the target vicinity. The working pressure can be decreased due to the increased plasma density, resulting in decreased collisional energy loss of the target bombarding ions in the gas phase, and thus enhanced sputtering rates. [38] A simple schematic drawing of a magnetron sputtering setup is shown in Fig. 2.1. Typical gas pressures used in magnetron sputtering are in the range of $100 \mathrm{mPa}-10 \mathrm{~Pa}$, depending on the dimensions of the sputtering system, affecting the pressure required to ignite and maintain a plasma. [39] Usually the magnets are arranged in a ring-like pattern, with one pole in the center and the opposite pole circling it. Figure 2.2 shows a balanced magnetron configuration, i.e., closed-loop magnetic field lines, which results in a dense plasma contained in the target vicinity. Enhanced sputtering over a certain area of the target may result in a so-called racetrack target erosion pattern. Additionally, an unbalanced magnetron setup can be used, resulting in open magnetic field lines and an increased plasma density away from the target, promoting ion bombardment of the growing film. The applied magnetic field configurations affect the ion-to-metal flux ratio arriving at the substrate, and can be used to tailor the morphology and properties of the growing film. [36, 37]

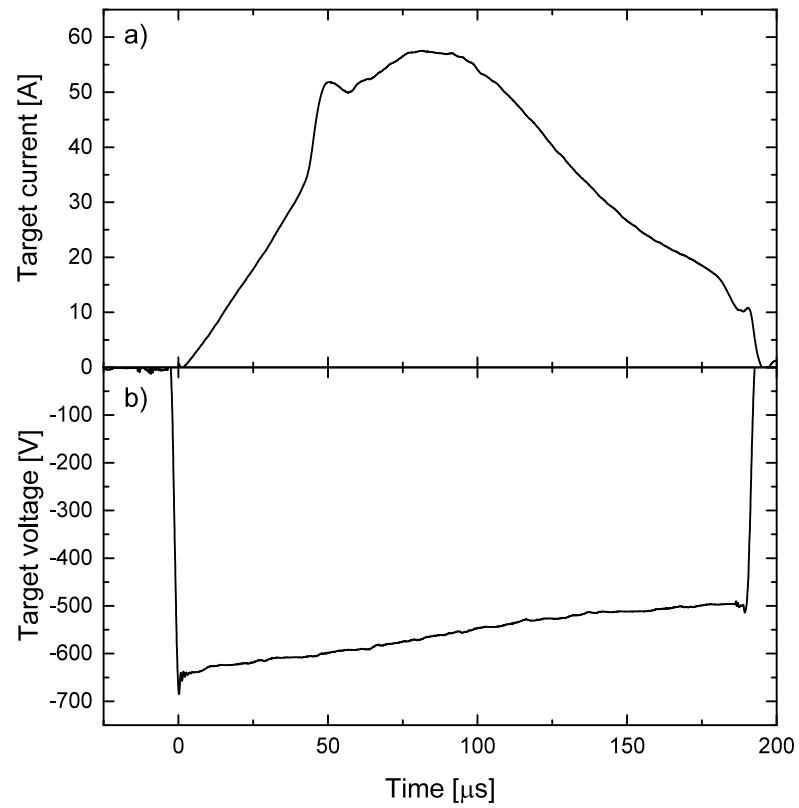

Figure 2.3. Target current and voltage waveforms recorded during a HiPIMS pulse of $200 \mu \mathrm{s}$. 


\subsubsection{High power impulse magnetron sputtering}

HiPIMS is an IPVD technique introduced in the late 1990's. [40] In HiPIMS the power to the cathode is delivered in short unipolar pulses with a relatively long halt time between the pulses $(\sim 1-10 \mathrm{~ms})$. The pulse frequencies used in HiPIMS can range from a few tens of $\mathrm{Hz}$ to a few $\mathrm{kHz}$, and the pulse on-time from a few microseconds to several hundreds of microseconds. The power on/off ratios during the cycle (duty cycle) vary from a few percent to a few tens of percent. The high energy delivered per pulse results in increased plasma densities in front of the target, which in turn leads to elevated amounts of ionized sputtered material due to electron impact ionization. In HiPIMS discharges the plasma density can reach values up to $10^{19}$ ions $/ \mathrm{cm}^{3}$, for dcMS discharges the peak plasma densities are two or three orders of magnitude lower. The use of high power pulses allows effective target cooling even when the power delivered to the cathode during the pulse ontime exceeds the time-averaged power by two orders of magnitude, and can reach values as high as several $\mathrm{kW} / \mathrm{cm}^{2}$. In direct current magnetron sputtering (dcMS) processes the target powers usually fall in the range of some tens or hundreds of $\mathrm{W} / \mathrm{cm}^{2}$. An example of a HiPIMS target current and voltage waveforms recorded for a process done with an average target power of $2400 \mathrm{~W}$, a frequency of $600 \mathrm{~Hz}$, a pulse width of $200 \mu \mathrm{s}$, and at a pressure of $400 \mathrm{mPa}$ employing a $\mathrm{N}_{2} \mathrm{O} / \mathrm{Ar}$ flow ratio of $12.8 \%$ is shown in Fig. 2.3. The target voltage is not constant throughout the pulse due to depletion of the capacitor bank of the power supply. [41-43]

Thin film processing by HiPIMS mostly relies on the increased portion of ionized target material when compared to dcMS. The higher degree of ionization of the sputtered material results in increased ion bombardment of the substrate and the growing film. [40, 44, 45] For this reason, HiPIMS is found to yield denser films with altered morphology, when compared to films grown by dcMS. [46] The energy and direction of the ionized flux arriving at the substrate can be controlled by electric or magnetic fields, allowing off-axis deposition on complex-shaped substrates. [47, 48] For example, the energy of the ions impinging on the substrate and the growing film can be tuned by adjusting the substrate bias voltage, thus affecting the microstructure and the residual stresses of the growing film. [45] This opens up a possibility to tailor the electrical and optical properties of the films, as these properties depend on the microstructure. [45, 49-52]

HiPIMS also has its limitations. One major drawback is the low deposition rate of some materials compared to dcMS, when both are operated at the same average target power. [53] The deposition rates for HiPIMS can be half of the dcMS rate or even lower for some metals, for example $\mathrm{Ti}, \mathrm{Al}$, and $\mathrm{Cr}$, though for some oxides, e.g., $\mathrm{ZrO}_{2}$ and $\mathrm{Ta}_{2} \mathrm{O}_{5}$, the HiPIMS deposition rate can exceed that obtained by dcMS. [41, 46, 54] Some explanations proposed for lowered deposition rates include magnetic confinement of the sputtered species [48], non-linear energetic dependence of the sputter yield [55], the effects caused by plasma conductivity [56], and back-attraction of charged target metal ions [57]. Another concern is the existence of multiply charged target metal ions, which are accelerated into higher kinetic energies by the substrate bias and can cause undesirable effects, such as ion implantation and higher residual stresses in the films. [58] 


\subsubsection{Reactive HiPIMS}

In reactive sputtering, the target is sputtered in the presence of one or more reactive gases. When a reactive gas, for example $\mathrm{O}_{2}$ or $\mathrm{N}_{2}$, is introduced to the chamber it is likely to react with the target surface by chemisorption and reactive ion implantation, and with the sputtered target material at the substrate as well as with the chamber walls, forming a compound. [59, 60]

The compound film formation at the target surface is known as target poisoning. [61] The transition between the metallic and poisoned target surface conditions is often observed as sudden changes in the cathode voltage and current, gas pressure, and deposition rate. [62,63] The high peak powers used in HiPIMS allow better control over the onset of target poisoning by efficiently removing the poisoned surface layer during the pulse. [64] Moreover, target poisoning by reactive gas ion implantation between the pulses is limited, reducing the compound formation on the target. [41, 64] This is an advantage compared to dcMS, as growth of stoichiometric compound films often requires the deposition process to be run in the transition regime between metallic and poisoned target surface conditions, to achieve both the desired composition and an ample deposition rate. [64, 65]

\subsubsection{HiPIMS in oxygen-containing atmospheres}

Oxygen is commonly used as a reactive gas in rHiPIMS of several oxides, or together with nitrogen to deposit oxynitrides. [64-66] The high reactivity of oxygen results in pronounced target poisoning, yielding highly unstable transition region conditions. Sputtering under poisoned target surface conditions often results in arcing of the target, and can produce undesirable macroparticles and decrease the film quality. $[67,68]$ Various reactive gas flow feedback systems, such as reactive gas partial pressure sensing and reactive gas pulsing, have been employed to maintain the process in the transition regime. $[54,69]$ Another possibility to achieve controllable deposition processes in the poisoned mode is to use arc suppression. [70, 71] Nonlinear target effects due to different reactivities of $\mathrm{O}_{2}$ and $\mathrm{N}_{2}$ are a common problem occurring in synthesis of oxynitrides by magnetron sputtering. [17, 19] Due to the higher reactivity of oxygen compared to nitrogen, it is more probable that the target is trapped into the poisoned state by oxygen if the reactive gas flows are not accurately controlled. [72] A pathway to achieve more controllable rHiPIMS deposition processes for $\mathrm{SiO}_{\mathrm{x}} \mathrm{N}_{\mathrm{y}}$ by using nitrous oxide $\left(\mathrm{N}_{2} \mathrm{O}\right)$ as a single-source precursor gas is presented in Papers I and II.

As an electronegative element, oxygen is found to exist in large percentages as $\mathrm{O}^{-}$in rHiPIMS plasmas. [73, 74] These negative ions are repelled by the applied negative cathode potential and can have deteriorating effects on film quality, depending on their origin and energy. [73, 75, 76] Low energy negative ions can be generated via electron attachment to gas atoms or molecules, dissociative electron attachment to gas molecules, or by fragmentation of the sputtered target compound. [74] Ion energies corresponding to the applied cathode potential of several hundreds of volts have been measured for $\mathrm{O}^{-}$ions originating from the target surface. [76] The $\mathrm{O}^{-}$ions existing in the afterglow of the rHiPIMS pulse can 
potentially contribute to the film oxygen uptake even during the pulse off-time. [73]

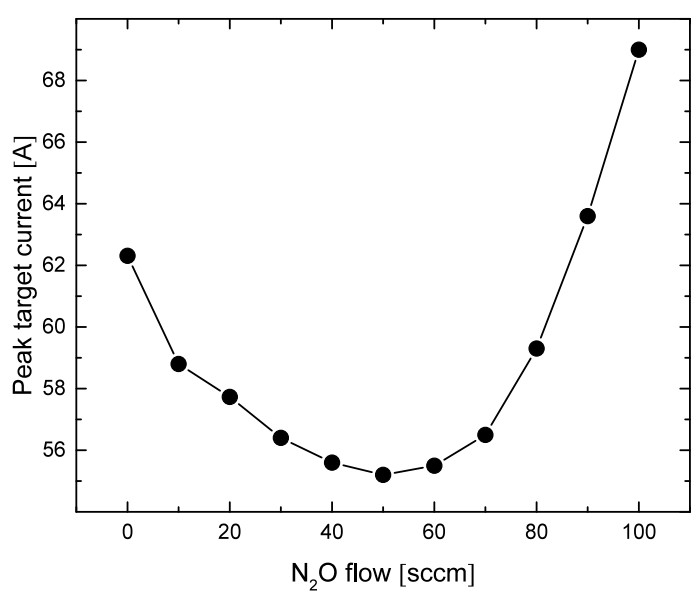

Figure 2.4. Peak target current as a function of $\mathrm{N}_{2} \mathrm{O}$ flow.

Compound formation at the target surface in the case of using silicon as a target material is observed as a rise in peak target current due to higher secondary electron yield of silicon oxide compared to silicon. $[77,78]$ Figure 2.4 shows the target current waveform evolution as the percentage of nitrous oxide in the plasma is increased, using an average target power of $4000 \mathrm{~W}$ and a pulse frequency of $1000 \mathrm{~Hz}$, at a pressure of $400 \mathrm{mPa}$. Initially, the peak target current decreases as more nitrous oxide is introduced. This can be attributed to the decreasing plasma density in front of the target and thus decreasing plasma conductivity [79-81], and to reduced secondary electron emission from silicon suboxides [62], limiting the current that can be drawn to the cathode. After a certain threshold the peak current starts increasing, indicating poisoned target surface conditions, because the secondary electron emission yield from completely oxidized silicon surface is higher than that from clean silicon or suboxides. [62, 77, 78]

\section{$2.2 \quad$ Langmuir probe}

Plasma parameters in the HiPIMS discharge can be measured by using a Langmuir probe. $[82,83]$ The probe has to be small to minimize perturbations caused to the plasma. As the probe bias is swept from negative to positive voltages, both ions and electrons are collected by the probe and an $I-V$ curve is recorded. These curves can be measured dynamically to record the $I-V$ curves during different stages of the pulse. An ideal $I-V$ curve is shown in Fig. 2.5. At the floating potential $\left(V_{f}\right)$ the ion and electron currents drawn by the probe are equal and probe current $\left(I_{p}\right)$ is nil. At the plasma potential $\left(V_{p}\right)$ the probe is in the same potential as the plasma itself, and the probe current is mostly resulting from electrons. [84] 


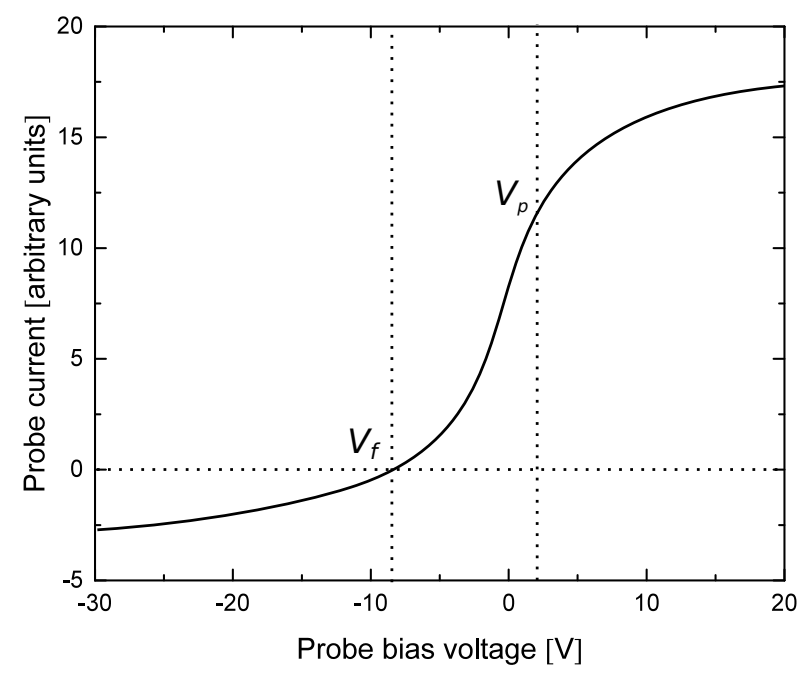

Figure 2.5. An ideal Langmuir probe $I-V$ curve, showing both $V_{f}$ and $V_{p}$.

Three different curve regions can be identified based on the applied probe bias $\left(V_{b}\right)$. When $V_{b}<V_{f}$, electrons are repelled and $I_{p}$ is mainly caused by ions, until the ion saturation current $\left(I_{i, s a t}\right)$ is reached at large negative $V_{b}$. At $V_{b}>V_{p}$, only negative charge carriers are being collected by the probe and eventually the electron saturation current $\left(I_{e, s a t}\right)$ is reached. [84]

Between $V_{f}$ and $V_{p}$, increasing amount of electrons are being collected by the probe. At a certain $V_{b}$ only those electrons that have enough energy to overcome the potential difference between the probe and the plasma are collected. In the case of a Maxwellian energy distribution of electrons, the electron current collected by the probe in this region follows equation (2.1):

$$
I_{e}=I_{e, s a t} \exp e \frac{V_{b}-V_{p}}{k_{B} T_{e}},
$$

where $k_{B}$ is the Boltzmann constant and $T_{e}$ is the average electron temperature. The slope of $\ln I_{e}$ versus $V_{p}$ yields the electron temperature. It is convenient to give $T_{e}$ in electronvolts, by using the inverse of the slope. [84]

\subsection{The effect of HiPIMS parameters on $\mathrm{SiO}_{x} \mathrm{~N}_{y}$ material properties}

The material properties of the $\mathrm{SiO}_{\mathrm{x}} \mathrm{N}_{\mathrm{y}}$ grown by HiPIMS in Papers I and II are found to depend on the amount and ratio of $\mathrm{O}$ and $\mathrm{N}$ in the material. The two main findings are that the film $\mathrm{N}$ content can be controlled by the $\mathrm{N}_{2} \mathrm{O}$ flow, and that the film $\mathrm{O}$ content can be controlled by the average target power. The effect of $\mathrm{N}_{2} \mathrm{O}$ flow and applied power on the film elemental composition is 
more clearly demonstrated in Paper II, where much higher $\mathrm{N}_{2} \mathrm{O} /$ Ar flow ratios $\left(f_{\mathrm{N}_{2} \mathrm{O} / \mathrm{Ar}}\right)$ were used $\left(f_{\mathrm{N}_{2} \mathrm{O} / \mathrm{Ar} \text {, max }} 22.2 \%\right)$ than in the studies conducted for Paper I $\left(f_{\mathrm{N}_{2} \mathrm{O} / \mathrm{Ar}, \max } 6.2 \%\right)$. In Paper II it is demonstrated that while the Si target is sputtered under poisoned target conditions at low average target powers $(1000 \mathrm{~W})$, the resulting film stoichiometry is approaching $\mathrm{SiO}_{2}$, whereas at higher average target powers $(2000-4000 \mathrm{~W})$ the film $\mathrm{N}$ content is found to be stable at $\sim 26$ at. $\%$ and the level of incorporated $\mathrm{O}$ is decreasing towards higher average powers. The effect of pulse frequency on film composition is not significant in this composition range (film total $\mathrm{O}+\mathrm{N}$ content above 30 at.\%) over the studied frequency range $(300-1000 \mathrm{~Hz})$.

The film optical properties are found to closely follow the film elemental composition, with the stoichiometric $\mathrm{SiO}_{\mathrm{x}} \mathrm{N}_{\mathrm{y}}$ films yielding $n$ and $k$ values between those of $\mathrm{SiO}_{2}$ and $\mathrm{Si}_{3} \mathrm{~N}_{4}(N \sim 1.5-2.2, k \sim 0$ at $633 \mathrm{~nm})$. The understoichiometric films show values that approach those of amorphous silicon, $n \sim 4.5, k \sim 0.38$, depending on the film film total $\mathrm{O}+\mathrm{N}$ content.

The residual stress in the films can also be affected by the deposition temperature and the substrate bias voltage. $\mathrm{A} \sim 25 \%$ decrease in the film residual stress was observed as the negative substrate bias was decreased from $-200 \mathrm{~V}$ to $-100 \mathrm{~V}$ or when the deposition temperature was increased from $\sim 350{ }^{\circ} \mathrm{C}$ to $\sim 500{ }^{\circ} \mathrm{C}$. These effects can be attributed to decreased energetic ion bombardment of the growing film and to more thermodynamically favorable film growth conditions, respectively, both leading into lower residual stresses in the film. [85] 
CHAPTER 3

Thin film characterization

Several analysis methods are required to characterize thin film properties. A set of techniques used to determine chemical composition, chemical bonding, mechanical properties, and optical properties of the films are presented in this chapter.

\subsection{X-ray photoelectron spectroscopy}

X-ray photoelectron spectroscopy (XPS) can be used to determine both the elemental composition and chemical bonding in the films. The operational principle of XPS is based on the photoelectric effect caused by soft X-rays, commonly $\mathrm{Al} \mathrm{K}_{\alpha}$ radiation $(h \nu=1486.6 \mathrm{eV})$. XPS is a surface sensitive technique, as the inelastic mean free path of photoelectrons is in the order of $\sim 5-10 \mathrm{~nm}$. The measurements have to be performed under ultra-high vacuum conditions to suppress adsorption of residual gas during analysis. [86]

Binding energies $\left(E_{b}\right)$ of the emitted photoelectrons can be determined according to equation (3.1), as their kinetic energies $\left(E_{k}\right)$ are measured and the photon energy $(h \nu)$ is known:

$$
E_{b}=h \nu-E_{k}-\phi,
$$

where $\phi$ is the spectrometer work function. [86]

Both the elemental composition and chemical bonding structure of the sample can be determined by the core level electron binding energies. Different elements have distinct core level binding energies that can be slightly influenced by the chemical environment of the atom, a phenomenon known as the chemical shift. For example, the core level electrons of an atom bonded to a more electronegative atom will have a stronger Coulomb interaction with the nucleus, as valence electrons are drawn towards the more electronegative element. Charge compensation can 
be applied in the case of dielectric samples, such as $\mathrm{SiO}_{\mathrm{x}} \mathrm{N}_{\mathrm{y}}$ films, because charge accumulation on the sample results in a shift of measured binding energies. [86]

The sample surface can be sputter cleaned with an ion beam etch to remove the oxidized surface layer and adventitious carbon occurring on most materials. A significant oxygen surplus in the elemental composition would be observed, if the elemental composition was to be determined from this oxidized surface layer. The energetic ions used for the sputter cleaning can, however, damage the chemical bonding structure and alter the composition in amorphous materials. The chemical bonding structure can instead be determined for as-received films, without applying sputter cleaning, thus avoiding possible alterations to the chemical bonding structure. [87]

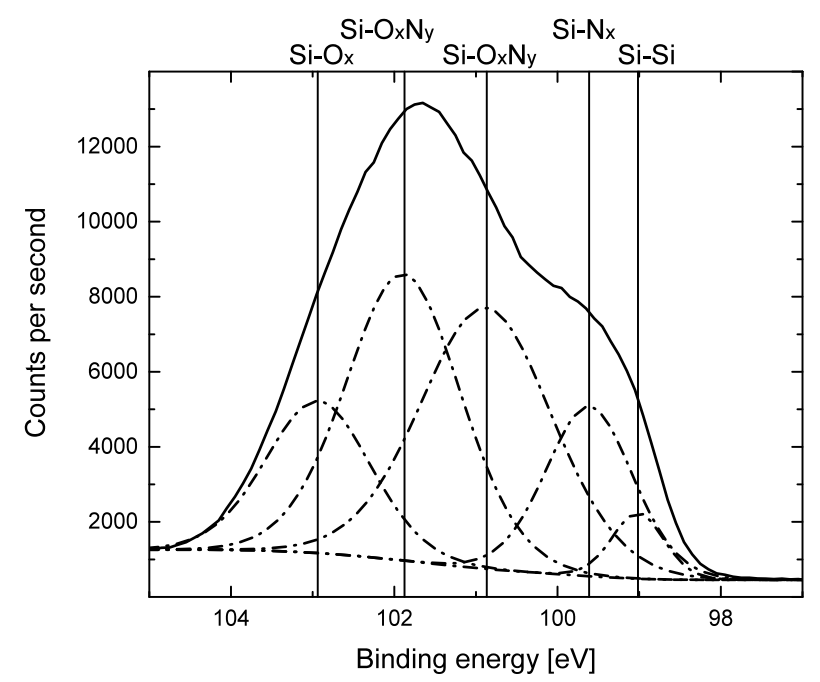

Figure 3.1. A XPS Si $2 p$ core level spectrum recorded for a $\mathrm{SiO}_{\mathrm{xNy}}$ film containing 27 at.\% and 17 at.\% of of $\mathrm{N}$ and $\mathrm{O}$, respectively. Five peaks can be fitted to the spectrum.

A peak fitting procedure has to be implemented to obtain information about the chemical bonding in the films. In compound films, the number of different chemically shifted contributions in the core level spectra of elements partaking in chemical bonding can be up to five, or even more in some cases. [88, 89] An example of a Si $2 \mathrm{p}$ core level spectrum obtained before a sputter clean for a $\mathrm{SiO}_{\mathrm{x}} \mathrm{N}_{\mathrm{y}}$ film containing 27 at.\% of $\mathrm{N}$ and 17 at.\% of $\mathrm{O}$, and fitted with a peak fit model consisting of five distinct peaks is shown in Fig. 3.1. Here, the different chemical bonding contributions can be assigned to $\mathrm{Si}-\mathrm{Si}$ bonds at $99 \mathrm{eV}, \mathrm{Si}-\mathrm{N}_{\mathrm{x}}$ bonds at $99.7 \mathrm{eV}, \mathrm{Si}-\mathrm{O}_{\mathrm{x}} \mathrm{N}_{\mathrm{y}}$ contributions at $100.9 \mathrm{eV}$ and $101.9 \mathrm{eV}$, and $\mathrm{Si}-\mathrm{O}_{\mathrm{x}}$ bonds at $102.9 \mathrm{eV}$. The $\mathrm{Si}-\mathrm{O}_{\mathrm{x}} \mathrm{N}_{\mathrm{y}}$ contributions have the largest FWHM values, as much as $1.8 \mathrm{eV}$, while for the $\mathrm{Si}-\mathrm{Si}$ bonds the peak FWHM is under $1 \mathrm{eV}$.

In $\mathrm{SiO}_{\mathrm{x}} \mathrm{N}_{\mathrm{y}}$ films, the number of different bonding contributions in the $\mathrm{Si} 2 \mathrm{p}$ core level spectra depends on the bonding model of the films. In the case of the film shown in Fig. 3.1, deposited at a relatively low temperature $\left(\lesssim 350{ }^{\circ} \mathrm{C}\right)$ by HiPIMS, 
both $\mathrm{N}$ and $\mathrm{O}$ are randomly distributed in the Si matrix. [88, 89] As silicon can form four bonds, multiple different bonding configurations with varying $x$ and $y$ in $\mathrm{SiO}_{\mathrm{x}} \mathrm{N}_{\mathrm{y}}$ are possible. This results in large peak widths for the components corresponding to $\mathrm{SiO}_{\mathrm{x}} \mathrm{N}_{\mathrm{y}}$ compositions. [88, 89]

\subsection{Elastic recoil detection analysis}

Elastic recoil detection analysis (ERDA) is an ion beam analysis method used to obtain thin film sample's elemental concentration depth profiles. In ERDA, high energy ion beam, such as $36 \mathrm{MeV}{ }^{127} \mathrm{I}^{8+}$ used in Paper I, is collided with the sample and the energies of forward-directed elastic recoils are measured. A time-of-flight ( $\mathrm{ToF}$ ) spectrometer can be used to differentiate between recoils having the same energy but different mass. The use of a ToF spectrometer also allows the determination of element depth profiles, as ions originating from below the sample surface lose some of their energy in collisions. [90]

The energy of a target atom with mass $M_{2}$ after an elastic collision with a projectile with mass $M_{1}$ and energy $E_{1}$ is given by equation (3.2):

$$
E_{2}=\frac{4 M_{1} M_{2} \cos ^{2} \theta}{\left(M_{1}+M_{2}\right)^{2}} E_{1}=K_{R} E_{1},
$$

where $\theta$ is the scattering angle and $K_{R}$ is the kinematic factor for elastic recoil. The maximum scattering angle depends on the ratio of the masses of the projectile and the target atom. The maximum scattering angle is given by equation (3.3): [91]

$$
\phi_{\max }=\arcsin \left(\frac{M_{2}}{M_{1}}\right) .
$$

As can be seen from (3.3), the amount of detectable elements for a certain sample depends on the system geometry and the choice of projectile. For film elemental compositions measured in Paper I, a $36 \mathrm{MeV}^{127} \mathrm{I}^{8+}$ ion beam at an angle of $22.5^{\circ}$ relative to the sample surface was used.

\subsection{X-ray reflectivity}

$\mathrm{X}$-ray reflectivity is a technique based on specular reflection of X-rays from surfaces and interfaces. The reflection is based on the different electron densities of the layers. The method can be used to determine thin film thickness, density, surface roughness, and multilayer structures in a glancing angle $\theta / 2 \theta$ configuration, where the incident and reflected angle are equal $(\omega=\theta)$. Below the critical angle $\theta_{c}$, the incident beam undergoes total external reflection. For $\theta>\theta_{c}$ the reflected intensity starts to fall and interference fringes are observed due to different path lengths of $\mathrm{X}$-rays scattered from different interfaces. For a monolayer film, equation (3.4) can be used to obtain the film thickness: [92]

$$
n \lambda=2 t \sin \theta \sqrt{1+\frac{\eta^{2}-1}{\sin ^{2} \theta}},
$$


where $n$ is an integer, $\lambda$ is the wavelength of incident $\mathrm{X}$-rays, $t$ is the film thickness, and $\eta$ is the film's complex refractive index. To asses properties such as density and surface roughness, the recorded data can be iteratively fitted with a suitable theoretical model of the sample, if the film composition is known. [93]

\subsection{Residual stress measurement}

The residual stresses in amorphous thin films can be determined by the wafer curvature method, using X-ray diffraction to obtain the substrate curvature after deposition. An assumption made here is that the residual stresses in the film have only uniform in-plane components, which is a reasonable approximation for amorphous films. [94]

The curved crystallographic planes in the stressed silicon substrate cause the angle of diffraction to shift along the rigid translation of the sample. When displacing the sample along the $x$-axis and maintaining the $2 \theta$-reflection, the radius of curvature of the substrate can be determined from the measured shift of the $\omega$-angle (the angle between the beam and the sample surface) as a function of the $x$-displacement. The specimen curvature is related to the change in orientation of the diffracted beam after displacement in the $x$-axis by equation (3.5): [95]

$$
\frac{1}{R}=\frac{\mathrm{d} \omega}{\mathrm{d} x},
$$

where $R$ is the radius of curvature of the specimen, $\mathrm{d} \omega$ is the change in the orientation of the diffracted beam, and $\mathrm{d} x$ is the sample displacement along the $x$-axis.

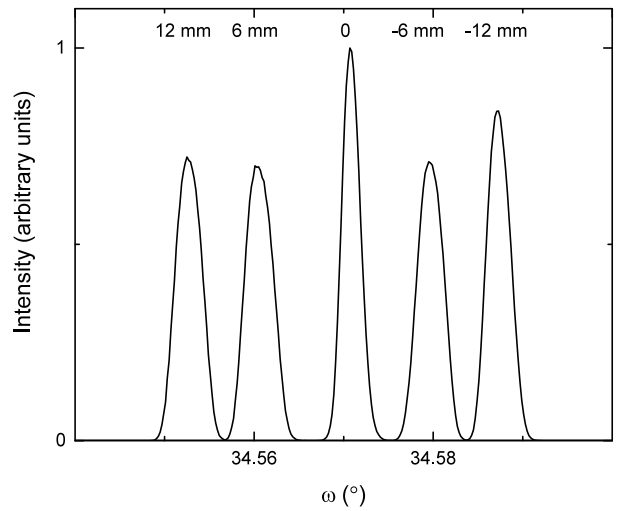

Figure 3.2. A measured shift in the angle between the X-ray beam and the sample surface, while maintaining the $2 \theta$-reflection, versus sample displacement.

The effect caused by intrinsic substrate curvature and possible erroneous stage translation can be determined by measuring the curvature of an uncoated substrate. 
The obtained value is subtracted from the curvature value measured for the coated specimen to obtain the true curvature:

$$
\frac{1}{R}=\frac{\mathrm{d} \omega}{\mathrm{d} x}-\frac{\mathrm{d} \omega}{\mathrm{d} x}_{\text {uncoated }}
$$

The radius of substrate curvature is then given by the slope of $x$-displacement versus the $\omega$-angle in radians. [95]

The measured substrate curvature can be related to the residual film stress by using the Stoney formula for anisotropic single crystal Si(001) lattice:

$$
\sigma_{f} t_{f}=\frac{h^{2}}{6\left(s_{11}^{\mathrm{Si}}+s_{12}^{\mathrm{Si}}\right) R},
$$

where $\sigma_{f}$ is the in-plane stress component of the film, $t_{f}$ is the film thickness, $h$ is substrate thickness, and the term $1 /\left(s_{11}^{\mathrm{Si}}+s_{12}^{\mathrm{Si}}\right)$ is the biaxial modulus of $\mathrm{Si}(001)$ $\left(1.803 \cdot 10^{11} \mathrm{~Pa}\right)$. [94, 96] An example of the $\omega$-angle versus sample displacement is shown in Fig. 3.2. With a film thickness of $\sim 420 \mathrm{~nm}$ the residual stress can be calculated to be approximately $-680 \mathrm{MPa}$, indicating compressive residual stress in the film.

\subsection{Spectroscopic ellipsometry}

Spectroscopic ellipsometry is a technique widely used for structural and optical characterization of thin films and surfaces. In the case of standard ellipsometry, the measured parameters are the ellipsometric angles $\Psi$ and $\Delta$. In reflection mode the state of polarization of light reflected from the sample is analyzed, when the incident light has a known polarization. The complex reflectance ratio $\rho$ between the $p$ and $s$ polarization planes can be linked to the measured angles by equation (3.8): [97]

$$
\rho=\frac{r_{p}}{r_{s}}=\tan \Psi \exp i \Delta,
$$

where $r_{p}$ and $r_{s}$ are the complex reflection coefficients for $p$ - and $s$-polarization, respectively.

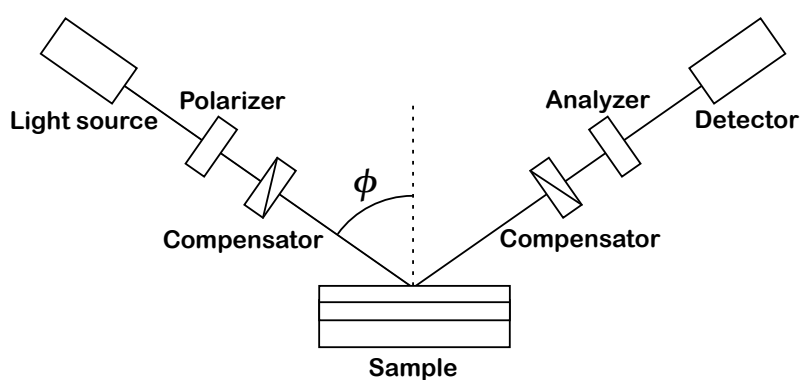

Figure 3.3. A schematic drawing of a dual rotating compensator spectroscopic ellipsometer. 
A dual rotating compensator ellipsometer setup can be used to measure the full Mueller matrix $\mathbf{M}$ of the sample. A Mueller matrix is a $4 \times 4$ matrix describing the polarization properties of an optical element interacting with the incident light. Measuring the Mueller matrix allows determination of depolarization effects, caused by, for example, nonuniform film thickness. A simple schematic of a dual rotating compensator ellipsometer setup is shown in Fig. 3.3. Unpolarized light is passed through a polarizer and a rotating compensator modulating the polarization, before being reflected from the sample. After being reflected, the light passes through a second rotating compensator and an analyzer before being detected. [97]

In the case of isotropic reflecting samples, such as amorphous $\mathrm{SiO}_{\mathrm{x}} \mathrm{N}_{\mathrm{y}}$ films, the number of non-zero elements in $\mathbf{M}$ decreases to 8 and $\mathbf{M}$ takes the following form: [97]

$$
\mathbf{M}=\left[\begin{array}{cccc}
1 & -N & 0 & 0 \\
-N & 1 & 0 & 0 \\
0 & 0 & C & S \\
0 & 0 & -S & C
\end{array}\right]
$$

The elements $N, C$, and $S$ can be related to the ellipsometric angles by relations (3.10) a-c:

$$
\begin{aligned}
& N=\cos 2 \Psi, \\
& C=\sin 2 \Psi \cos \Delta, \\
& S=\sin 2 \Psi \sin \Delta .
\end{aligned}
$$

For $N, C$, and $S$ it holds that

$$
N^{2}+C^{2}+S^{2}=1
$$

The $N, C$, and $S$ can also be connected to equation (3.8) by equation (3.11): [97]

$$
\rho=\frac{r_{p}}{r_{s}}=\frac{C+i S}{1+N}=\tan \Psi \exp i \Delta .
$$

In most cases the ellipsometric measurement is indirect, and does not yield the sample's structural properties, but they have to obtained by iteratively fitting the data with a suitable model including the possible layers and interfaces in the sample. In the case of amorphous $\mathrm{SiO}_{\mathrm{x}} \mathrm{N}_{\mathrm{y}}$ films, the Tauc-Lorentz (TL) dispersion model was used to model the complex dielectric function $\left(\epsilon=\epsilon_{1}+i \epsilon_{2}\right)$ of the films to obtain their refractive indices $n$ and extinction coefficients $k$. [98, 99] Both $n$ and $k$ can be calculated from $\epsilon$, as $\epsilon_{1}=N^{2}-k^{2}$ and $\epsilon_{2}=2 n k$. In TL model, $\epsilon_{2}$ has the following expression above the band gap energy:

$$
\epsilon_{2}=\frac{1}{E} \frac{A E_{0} C\left(E-E_{g}\right)^{2}}{\left(E^{2}-E_{0}^{2}\right)^{2}+C^{2} E^{2}}, E>E_{g},
$$

where $E$ is the photon energy, $A$ the peak amplitude, $E_{g}$ is the band gap energy, $E_{0}$ is the peak transition energy, and $C$ is a broadening term. Below the band gap energy $\epsilon_{2}=0$. The real part of the dielectric function, $\epsilon_{1}$, can be calculated from $\epsilon_{2}$ by using Kramers-Kronig integration. [98] 
The measure of how well the model fits the measured data is quantified by mean squared error (MSE). The MSE is minimized by iteratively fitting the constructed model to the measured data. However, the smallest MSE does not necessarily implicate that the used model is correct. The model has to also yield physically meaningful results for the layer thicknesses, for example. [97] 
CHAPTER 4

Results and included papers

\subsection{List of publications}

I Silicon oxynitride films deposited by reactive high power impulse magnetron sputtering using nitrous oxide as a single-source precursor

T. Hänninen, S. Schmidt, J. Jensen, L. Hultman and H. Högberg Journal of Vacuum Science and Technology A 33, 05E121 (2015).

II Stoichiometric silicon oxynitride thin films reactively sputtered in Ar $/ \mathrm{N}_{2} \mathrm{O}$ plasmas by HiPIMS

T. Hänninen, S. Schmidt, J. Wissting, J. Jensen, L. Hultman and H. Högberg

Submitted for publication. 


\subsection{Summary of included papers}

\section{Paper I}

A new synthesis route for $\mathrm{SiO}_{\mathrm{x}} \mathrm{N}_{\mathrm{y}}$ thin films by rHiPIMS, using $\mathrm{N}_{2} \mathrm{O}$ as a single-source precursor gas, is presented. The films were characterized based on their chemical, optical, and mechanical properties. The changes in film elemental composition were related to the used deposition parameters through target poisoning mechanisms occurring during the process when $\mathrm{N}_{2} \mathrm{O}$ is introduced to the system.

\section{Paper II}

Effectively stoichiometric $\mathrm{SiO}_{\mathrm{x}} \mathrm{N}_{\mathrm{y}}$ thin films, meaning no observable $\mathrm{Si}-\mathrm{Si}$ chemical bonding contributions the XPS Si $2 p$ spectra, were synthesized by rHiPIMS. The optical properties of these stoichiometric are shown to fall in between those of $\mathrm{SiO}_{2}$ and $\mathrm{Si}_{3} \mathrm{~N}_{4}$. Favorable film deposition conditions can be established in the transition and poisoned target surface regimes, based on the analysis of the target current behavior and plasma properties upon the introduction of $\mathrm{N}_{2} \mathrm{O}$. 
[1] S. Callard, A. Gagnaire, and J. Joseph. "Characterization of graded refractive index silicon oxynitride thin films by spectroscopic ellipsometry". In: Thin Solid Films 313-314.0 (1998), pp. 384-388.

[2] H. Bartzsch et al. "Graded refractive index layer systems for antireflective coatings and rugate filters deposited by reactive pulse magnetron sputtering". In: Surface and Coatings Technology 180-181 (2004), pp. 616-620.

[3] B.S. Sahu et al. "Influence of hydrogen on losses in silicon oxynitride planar optical waveguides". In: Semiconductor Science and Technology 15.3 (2000), p. L11.

[4] C. Gorecki et al. "Characterization of internal stress of silicon oxinitride thin films fabricated by plasma-enhanced chemical vapor deposition: applications in integrated optics". In: Proceedings of SPIE 4596 (2001), pp. 9-15.

[5] S. Arulkumaran et al. "Surface passivation effects on AlGaN/GaN highelectron-mobility transistors with $\mathrm{SiO}_{2}, \mathrm{Si}_{3} \mathrm{~N}_{4}$, and silicon oxynitride". In: Applied Physics Letters 84.4 (2004), pp. 613-615.

[6] J. Dupuis et al. "Impact of PECVD SiON stoichiometry and post-annealing on the silicon surface passivation". In: Thin Solid Films 516.20 (2008), pp. 69546958.

[7] R.M. de Ridder et al. "Silicon oxynitride planar waveguiding structures for application in optical communication". In: Selected Topics in Quantum Electronics, IEEE Journal of 4.6 (1998), pp. 930-937.

[8] M.I. Alayo et al. "Deposition and characterization of silicon oxynitride for integrated optical applications". In: Journal of Non-Crystalline Solids 338-340 (2004), pp. 76-80.

[9] Y. Liu, I.-K. Lin, and X. Zhang. "Mechanical properties of sputtered silicon oxynitride films by nanoindentation". In: Materials Science and Engineering: A 489.1-2 (2008), pp. 294-301. 
[10] D. Criado et al. "Study of the mechanical and structural properties of silicon oxynitride films for optical applications". In: Journal of Non-Crystalline Solids 352.23-25 (2006), pp. 2319-2323.

[11] G.J. Wan et al. "Si-N-O Films Synthesized by Plasma Immersion Ion Implantation and Deposition (PIII\&D) for Blood-Contacting Biomedical Applications". In: Plasma Science, IEEE Transactions on 34.4 (2006), pp. 1160-1165.

[12] M. Fenker. "Properties of oxynitride thin films for bio-medical applications," in: Metallic Oxynitride Thin Films by Reactive Sputtering and Related Deposition Methods: Processes, Properties and Applications: ed. by F. Vaz, N. Martin, and M. Fenker. Bentham Science Publishers, 2013, pp. 254-264.

[13] K. Wörhoff et al. "Silicon Oxynitride: A Versatile Material for Integrated Optics Applications". In: Journal of The Electrochemical Society 149.8 (2002), F85-F91.

[14] E.C. Samano, J. Camacho, and R. Machorro. "Optimal control on composition and optical properties of silicon oxynitride thin films". In: Journal of Vacuum Science \& Technology A 23.4 (2005), pp. 1228-1233.

[15] C. Ance et al. "Optical absorption in plasma-deposited silicon oxynitride films". In: Applied Physics Letters 60.11 (1992), pp. 1399-1401.

[16] T. Kanata, H. Takakura, and Y. Hamakawa. "Preparation of compositioncontrolled silicon oxynitride films by sputtering; deposition mechanism, and optical and surface properties". In: Applied Physics A 49.3 (1989), pp. 305311.

[17] E. Aubry et al. "Silicon oxynitride thin films synthesised by the reactive gas pulsing process using rectangular pulses". In: Applied Surface Science 257.23 (2011), pp. 10065-10071.

[18] V. Godinho, T.C. Rojas, and A. Fernandez. "Magnetron sputtered a- $\mathrm{SiO}_{x} \mathrm{~N}_{y}$ thin films: A closed porous nanostructure with controlled optical and mechanical properties". In: Microporous and Mesoporous Materials 149.1 (2012), pp. $142-146$.

[19] N. Martin and C. Rousselot. "Instabilities of the reactive sputtering process involving one metallic target and two reactive gases". In: Journal of Vacuum Science \& Technology A 17.5 (1999), pp. 2869-2878.

[20] J. Weber, H. Bartzsch, and P. Frach. "Sputter deposition of silicon oxynitride gradient and multilayer coatings". In: Applied Optics 47.13 (2008), pp. C288C292.

[21] Y.-N. Xu and W.Y. Ching. "Electronic structure and optical properties of $\alpha$ and $\beta$ phases of silicon nitride, silicon oxynitride, and with comparison to silicon dioxide". In: Physical Review B 51 (24 1995), pp. 17379-17389.

[22] M.L. Green et al. "Ultrathin $(<4 \mathrm{~nm}) \mathrm{SiO}_{2}$ and $\mathrm{Si}-\mathrm{O}-\mathrm{N}$ gate dielectric layers for silicon microelectronics: Understanding the processing, structure, and physical and electrical limits". In: Journal of Applied Physics 90.5 (2001), pp. 2057-2121. 
[23] V.A. Gritsenko et al. "Short-range order in non-stoichiometric amorphous silicon oxynitride and silicon-rich nitride". In: Journal of Non-Crystalline Solids 297.1 (2002), pp. 96-101.

[24] S. Hasegawa et al. "Structure of defects in silicon oxynitride films". In: Journal of Applied Physics 89.5 (2001), pp. 2598-2605.

[25] F. Rebib et al. " $\mathrm{SiO}_{x} \mathrm{~N}_{y}$ thin films deposited by reactive sputtering: Process study and structural characterisation". In: Thin Solid Films 515.7-8 (2007), pp. 3480-3487.

[26] M. Serényi, M. Rácz, and T. Lohner. "Refractive index of sputtered silicon oxynitride layers for antireflection coating". In: Vacuum 61.2-4 (2001), pp. 245-249.

[27] D.M. Brown et al. "Properties of $\mathrm{Si}_{x} \mathrm{O}_{y} \mathrm{~N}_{z}$ Films on Si". In: Journal of The Electrochemical Society 115.3 (1968), pp. 311-317.

[28] T. Roschuk et al. "Optical and compositional characterization of $\mathrm{SiO}_{x} \mathrm{~N}_{y}$ and $\mathrm{SiO}_{x}$ thin films deposited by electron cyclotron resonance plasma enhanced chemical vapor deposition". In: Journal of Vacuum Science \& Technology A 22.3 (2004), pp. 883-886.

[29] S. Kohli et al. "Spectroscopic ellipsometry and photoluminescence measurements of as-deposited and annealed silicon rich oxynitride films". In: Thin Solid Films 516.12 (2008), pp. 4342-4350.

[30] N. Do et al. "Temperature dependence of optical constants for amorphous silicon". In: Applied Physics Letters 60.18 (1992), pp. 2186-2188.

[31] A. Bender et al. "X-ray reflectivity study of r.f.-sputtered thin $\mathrm{SiO}_{2}$ films". In: Thin Solid Films 229.1 (1993), pp. 29-32.

[32] T. Serikawa and A. Okamoto. "Properties of Magnetron-Sputtered Silicon Nitride Films". In: Journal of The Electrochemical Society 131.12 (1984), pp. 2928-2933.

[33] M. Vila, D. Cáceres, and C. Prieto. "Mechanical properties of sputtered silicon nitride thin films". In: Journal of Applied Physics 94.12 (2003), pp. 78687873 .

[34] M. Ohring. Materials Science of Thin Films. Burlington, MA, USA: Academic Press, 2001.

[35] D. Lundin and K. Sarakinos. "An introduction to thin film processing using high-power impulse magnetron sputtering". In: Journal of Materials Research 27 (05 2012), pp. 780-792.

[36] D.M. Mattox. Handbook of Physical Vapor Deposition (PVD) Processing. Elsevier Science, 2010.

[37] K. Wasa. Handbook of Sputter Deposition Technology: Fundamentals and Applications for Functional Thin Films, Nano-materials and MEMS. William Andrew, 2012. 
[38] D.M. Mattox et al. "Technical note: Design and performance of a movable post-cathode magnetron sputtering system for making PBFA II accelerator ion sources". In: Surface and Coatings Technology 33.0 (1987), pp. 425-432.

[39] W.D. Gill and E. Kay. "Efficient Low Pressure Sputtering in a Large Inverted Magnetron Suitable for Film Synthesis". In: Review of Scientific Instruments 36.3 (1965), pp. 277-282.

[40] V. Kouznetsov et al. "A novel pulsed magnetron sputter technique utilizing very high target power densities". In: Surface and Coatings Technology 122.2-3 (1999), pp. 290-293.

[41] K. Sarakinos, J. Alami, and S. Konstantinidis. "High power pulsed magnetron sputtering: A review on scientific and engineering state of the art". In: Surface and Coatings Technology 204.11 (2010), pp. 1661-1684.

[42] A. Anders. "Discharge physics of high power impulse magnetron sputtering". In: Surface and Coatings Technology 205, Supplement 2.0 (2011), S1-S9.

[43] J.T. Gudmundsson et al. "High power impulse magnetron sputtering discharge". In: Journal of Vacuum Science \& Technology A 30.3, 030801 (2012).

[44] J.T. Gudmundsson, J. Alami, and U. Helmersson. "Spatial and temporal behavior of the plasma parameters in a pulsed magnetron discharge". In: Surface and Coatings Technology 161.2-3 (2002), pp. 249-256.

[45] G. Greczynski et al. "Microstructure control of $\mathrm{CrN}_{x}$ films during high power impulse magnetron sputtering". In: Surface and Coatings Technology 205.1 (2010), pp. 118-130.

[46] M. Samuelsson et al. "On the film density using high power impulse magnetron sputtering". In: Surface and Coatings Technology 205.2 (2010), pp. 591-596.

[47] J. Alami et al. "Ion-assisted physical vapor deposition for enhanced film properties on nonflat surfaces". In: Journal of Vacuum Science \& Technology A 23.2 (2005), pp. 278-280.

[48] J. Böhlmark et al. "Guiding the deposition flux in an ionized magnetron discharge". In: Thin Solid Films 515.4 (2006), pp. 1928-1931.

[49] A.P. Ehiasarian et al. "High power pulsed magnetron sputtered $\mathrm{CrN}_{x}$ films". In: Surface and Coatings Technology 163-164.0 (2003), pp. 267-272.

[50] A.P. Ehiasarian et al. "Comparison of microstructure and mechanical properties of chromium nitride-based coatings deposited by high power impulse magnetron sputtering and by the combined steered cathodic arc/unbalanced magnetron technique". In: Thin Solid Films 457.2 (2004), pp. 270-277.

[51] J. Alami et al. "On the relationship between the peak target current and the morphology of chromium nitride thin films deposited by reactive high power pulsed magnetron sputtering". In: Journal of Physics D: Applied Physics 42.1 (2009), p. 015304.

[52] R.C. Munoz et al. "Surface-induced resistivity of thin metallic films bounded by a rough fractal surface". In: Physical Review B 66 (20 2002), p. 205401. 
[53] U. Helmersson et al. "Ionized physical vapor deposition (IPVD): A review of technology and applications". In: Thin Solid Films 513.1-2 (2006), pp. 1-24.

[54] J. Vlček et al. "Process stabilization and a significant enhancement of the deposition rate in reactive high-power impulse magnetron sputtering of $\mathrm{ZrO}_{2}$ and $\mathrm{Ta}_{2} \mathrm{O}_{5}$ films". In: Surface and Coatings Technology 236 (2013), pp. 550556.

[55] J. Emmerlich et al. "The physical reason for the apparently low deposition rate during high-power pulsed magnetron sputtering". In: Vacuum 82.8 (2008), pp. 867-870.

[56] S. Konstantinidis et al. "Transport of ionized metal atoms in high-power pulsed magnetron discharges assisted by inductively coupled plasma". In: Applied Physics Letters 88.2, 021501 (2006).

[57] D.J. Christie. "Target material pathways model for high power pulsed magnetron sputteringa)". In: Journal of Vacuum Science \& Technology A 23.2 (2005), pp. 330-335.

[58] G. Greczynski et al. "Role of $\mathrm{Ti}^{n+}$ and $\mathrm{Al}^{n+}$ ion irradiation $(n=1,2)$ during $\mathrm{Ti}_{1-x} \mathrm{Al}_{x} \mathrm{~N}$ alloy film growth in a hybrid HIPIMS/magnetron mode". In: Surface and Coatings Technology 206.19-20 (2012), pp. 4202-4211.

[59] D. Depla and R. De Gryse. "Target poisoning during reactive magnetron sputtering: Part I: the influence of ion implantation". In: Surface and Coatings Technology 183.2-3 (2004), pp. 184-189.

[60] D. Depla and R. De Gryse. "Target poisoning during reactive magnetron sputtering: Part II: the influence of chemisorption and gettering". In: Surface and Coatings Technology 183.2-3 (2004), pp. 190-195.

[61] S. Berg et al. "Process modeling of reactive sputtering". In: Journal of Vacuum Science \& Technology A 7.3 (1989), pp. 1225-1229.

[62] D. Depla et al. "Understanding the discharge voltage behavior during reactive sputtering of oxides". In: Journal of Applied Physics 101.1, 013301 (2007).

[63] D. Depla, S. Mahieu, and R. De Gryse. "Magnetron sputter deposition: Linking discharge voltage with target properties". In: Thin Solid Films 517.9 (2009), pp. 2825-2839.

[64] E. Wallin and U. Helmersson. "Hysteresis-free reactive high power impulse magnetron sputtering". In: Thin Solid Films 516.18 (2008), pp. 6398-6401.

[65] K. Sarakinos et al. "Process stabilization and enhancement of deposition rate during reactive high power pulsed magnetron sputtering of zirconium oxide". In: Surface and Coatings Technology 202.20 (2008), pp. 5033-5035.

[66] J. Rezek et al. "High-rate reactive high-power impulse magnetron sputtering of Ta-O-N films with tunable composition and properties". In: Thin Solid Films 566 (2014), pp. 70-77.

[67] M. Aiempanakit et al. "Hysteresis and process stability in reactive high power impulse magnetron sputtering of metal oxides". In: Thin Solid Films 519.22 (2011), pp. 7779-7784. 
[68] M. Aiempanakit et al. "Understanding the discharge current behavior in reactive high power impulse magnetron sputtering of oxides". In: Journal of Applied Physics 113.13, 133302 (2013).

[69] M. Audronis, V. Bellido-Gonzalez, and B. Daniel. "Control of reactive high power impulse magnetron sputtering processes". In: Surface and Coatings Technology 204.14 (2010), pp. 2159-2164.

[70] M. Hála et al. "Hysteresis-free deposition of niobium oxide films by HiPIMS using different pulse management strategies". In: Journal of Physics D: Applied Physics 45.5, 055204 (2012).

[71] M. Hála et al. "Reactive HiPIMS deposition of $\mathrm{SiO}_{2} / \mathrm{Ta}_{2} \mathrm{O}_{5}$ optical interference filters". In: Journal of Applied Physics 116.21, 213302 (2014).

[72] N. Martin et al. "Correlation between processing and properties of $\mathrm{TiO}_{x} \mathrm{~N}_{y}$ thin films sputter deposited by the reactive gas pulsing technique". In: Applied Surface Science 185.1-2 (2001), pp. 123-133.

[73] M. Bowes and J.W. Bradley. "The behaviour of negative oxygen ions in the afterglow of a reactive HiPIMS discharge". In: Journal of Physics D: Applied Physics 47.26 (2014), p. 265202.

[74] M. Bowes, P. Poolcharuansin, and J.W. Bradley. "Negative ion energy distributions in reactive HiPIMS". In: Journal of Physics D: Applied Physics 46.4 (2013), p. 045204.

[75] S. Mráz and J.M. Schneider. "Influence of the negative oxygen ions on the structure evolution of transition metal oxide thin films". In: Journal of Applied Physics 100.2, 023503 (2006).

[76] S. Mráz and J.M. Schneider. "Energy distribution of $\mathrm{O}^{-}$ions during reactive magnetron sputtering". In: Applied Physics Letters 89.5, 051502 (2006).

[77] R.A. Baragiola et al. "Ion-induced electron emission from clean metals". In: Surface Science 90.2 (1979), pp. 240-255.

[78] K. Wittmaack. "Ion-induced electron emission as a means of studying energyand angle-dependent compositional changes of solids bombarded with reactive ions: I. Oxygen bombardment of silicon". In: Surface Science 419.2-3 (1999), pp. 249-264.

[79] A. Karpinski et al. "Deposition of nickel oxide by direct current reactive sputtering: Effect of oxygen partial pressure". In: Thin Solid Films 520.9 (2012), pp. 3609-3613.

[80] J.C. Sagás, D.A. Duarte, and S.F. Fissmer. "Effect of oxygen concentration and system geometry on the current-voltage relations during reactive sputter deposition of titanium dioxide thin films". In: Vacuum 85.11 (2011), pp. 10421046.

[81] F. Magnus et al. "Current-voltage-time characteristics of the reactive $\mathrm{Ar} / \mathrm{O}_{2}$ high power impulse magnetron sputtering discharge". In: Journal of Vacuum Science \& Technology A 30.5, 050601 (2012). 
[82] A. Vetushka and A.P. Ehiasarian. "Plasma dynamic in chromium and titanium HIPIMS discharges". In: Journal of Physics D: Applied Physics 41.1 (2008), p. 015204.

[83] J.T. Gudmundsson et al. "On the electron energy in the high power impulse magnetron sputtering discharge". In: Journal of Applied Physics 105.12, $123302(2009)$.

[84] F.F. Chen. "Langmuir probe diagnostics". In: IEEE-ICOPS Meeting, Jeju, Korea. 2003.

[85] F.M. D'Heurle and J.M.E. Harper. "Note on the origin of intrinsic stresses in films deposited via evaporation and sputtering". In: Thin Solid Films 171.1 (1989), pp. 81-92.

[86] P. van der Heide. X-Ray Photoelectron Spectroscopy : An Introduction to Principles and Practices. Hoboken, NJ, USA: John Wiley \& Sons, 2011.

[87] S. Oswald and R. Reiche. "Binding state information from XPS depth profiling: capabilities and limits". In: Applied Surface Science 179.1-4 (2001), pp. 307315 .

[88] P. Cova et al. "A method for the analysis of multiphase bonding structures in amorphous $\mathrm{SiO}_{x} \mathrm{~N}_{y}$ films". In: Journal of Applied Physics 97.7, 073518 (2005).

[89] P. Cova, S. Poulin, and R.A. Masut. "X-ray photoelectron spectroscopy and structural analysis of amorphous $\mathrm{SiO}_{x} \mathrm{~N}_{y}$ films deposited at low temperatures". In: Journal of Applied Physics 98.9, 094903 (2005).

[90] O. Benka. "Elastic Recoil Detection Analysis (ERDA)". In: Surface and Thin Film Analysis. Ed. by G. Friedbacher and H. Bubert. Wiley-VCH Verlag GmbH \& Co. KGaA, 2011, pp. 217-227.

[91] G. Dollinger et al. "High resolution depth profile analysis by elastic recoil detection with heavy ions". In: Fresenius' Journal of Analytical Chemistry 353.3-4 (1995), pp. 311-315.

[92] G.V. Pavlinsky. Fundamentals of X-Ray Physics. Cambridge, GBR: Cambridge International Science Publishing, 2008.

[93] P.N. Gibson. "Grazing Incidence X-Ray Methods for Near-Surface Structural Studies". In: Surface and Thin Film Analysis. Ed. by G. Friedbacher and H. Bubert. Wiley-VCH Verlag GmbH \& Co. KGaA, 2011, pp. 311-327.

[94] B. Freund and S. Suresh. Thin Film Materials: Stress, Defect Formation and Surface Evolution. West Nyack, NY, USA: Cambridge University Press, 2004.

[95] A.J. Rosakis et al. "Full field measurements of curvature using coherent gradient sensing: application to thin film characterization". In: Thin Solid Films 325.1-2 (1998), pp. 42-54.

[96] G.C.A.M. Janssen et al. "Celebrating the 100th anniversary of the Stoney equation for film stress: Developments from polycrystalline steel strips to single crystal silicon wafers". In: Thin Solid Films 517.6 (2009), pp. 18581867. 
[97] H. Tompkins and E.A. Irene. Handbook of Ellipsometry. Elsevier Science, 2005.

[98] G.E. Jellison and F.A. Modine. "Parameterization of the optical functions of amorphous materials in the interband region". In: Applied Physics Letters 69.3 (1996), pp. 371-373.

[99] G.E. Jellison et al. "Spectroscopic ellipsometry characterization of thin-film silicon nitride". In: Thin Solid Films 313-314.0 (1998), pp. 193-197. 


\section{Papers}

The articles associated with this thesis have been removed for copyright reasons. For more details about these see:

http://urn.kb.se/resolve?urn=urn:nbn:se:liu:diva-123383 